\title{
A young man with palpitations and Ebstein's anomaly of the tricuspid valve
}

CASE: A 28-year-old previously healthy man presented with a 6-week history of palpitations. The symptoms occurred during rest, 2-3 times per week, lasted up to 30 minutes at a time and were associated with dyspnea. Except for a grade 2/6 holosystolic tricuspid regurgitation murmur (best heard at the left sternal border with inspiratory accentuation), physical examination yielded unremarkable findings. An electrocardiogram (ECG) revealed normal sinus rhythm and a Wolff-Parkinson-White pre-excitation pattern (Fig. 1: Top), produced by a right-sided accessory pathway. Transthoracic echocardiography demonstrated the presence of Ebstein's anomaly of the tricuspid valve, with apical displacement of the valve and formation of an "atrialized" right ventricle (a functional unit between the right atrium and the inlet [inflow] portion of the right ventricle) (Fig. 2). The anterior tricuspid valve leaflet was elongated (Fig. 2C, arrow), whereas the septal leaflet was rudimentary (Fig. 2C, arrowhead). Contrast echocardiography using saline revealed a patent foramen ovale with right-to-left shunting and bubbles in the left atrium (Fig. 2D).

The patient underwent an electrophysiologic study with mapping of the accessory pathway, followed by radiofrequency ablation (interruption of the pathway using the heat generated by electromagnetic waves at the tip of an ablation catheter). His post-ablation ECG showed a prolonged PR interval and an odd "second" QRS complex in leads III, aVF and $\mathrm{V}_{2}-\mathrm{V}_{4}$ (Fig. 1: Bottom), a consequence of abnormal impulse conduction in the "atrialized" right ventricle. The patient reported no recurrence of palpitations at follow-up 6 months after the ablation.

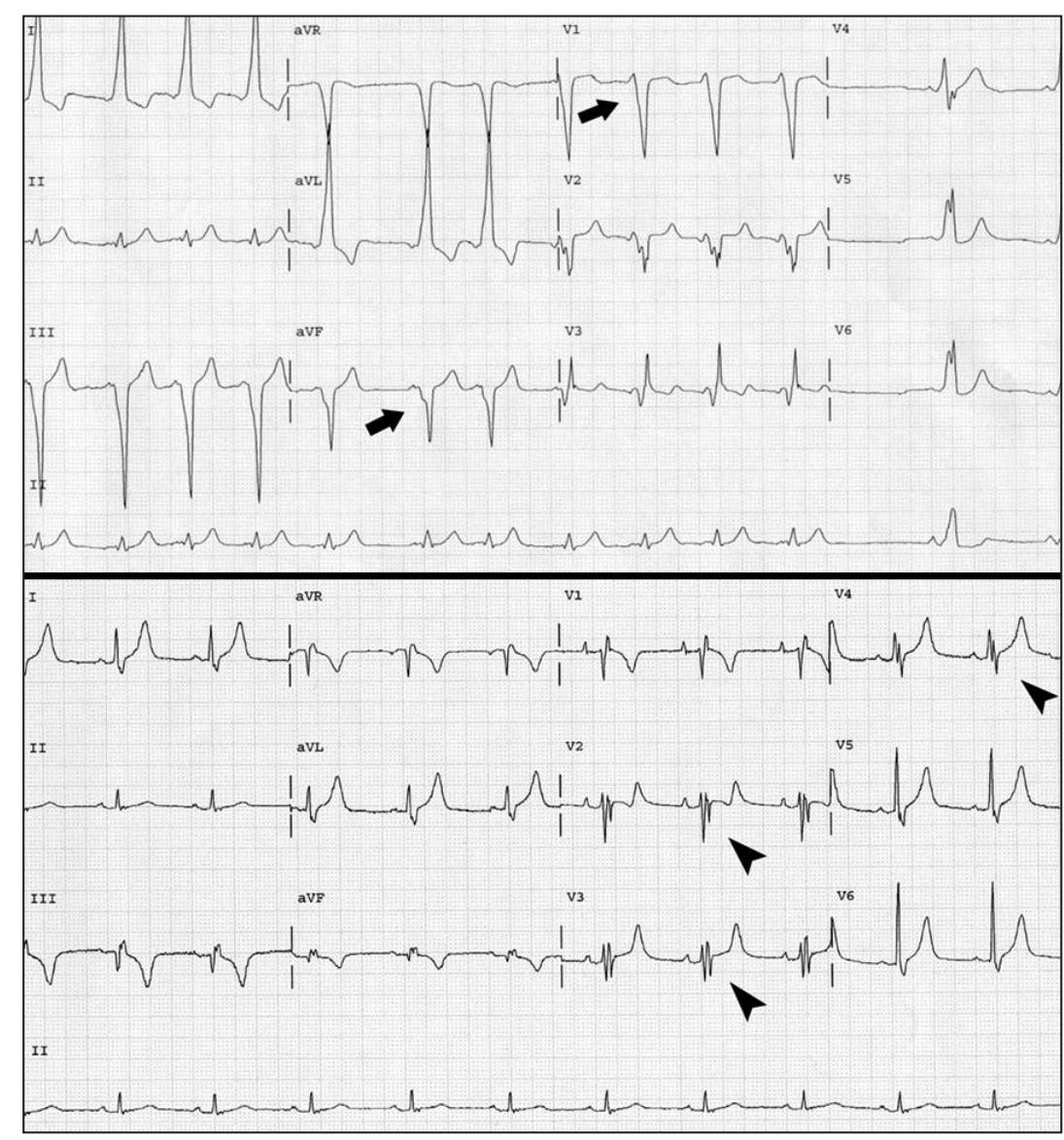

Fig. 1: Top: Electrocardiogram from patient with Ebstein's anomaly of the tricuspid valve, showing shortened PR interval, prolonged QRS interval and delta waves (arrows). Bottom: Electrocardiogram after radiofrequency ablation, showing prolonged PR interval and odd "second" QRS complex in leads III, aVF and $V_{2}-V_{4}$ (arrowheads), a consequence of abnormal impulse conduction in the "atrialized" right ventricle.
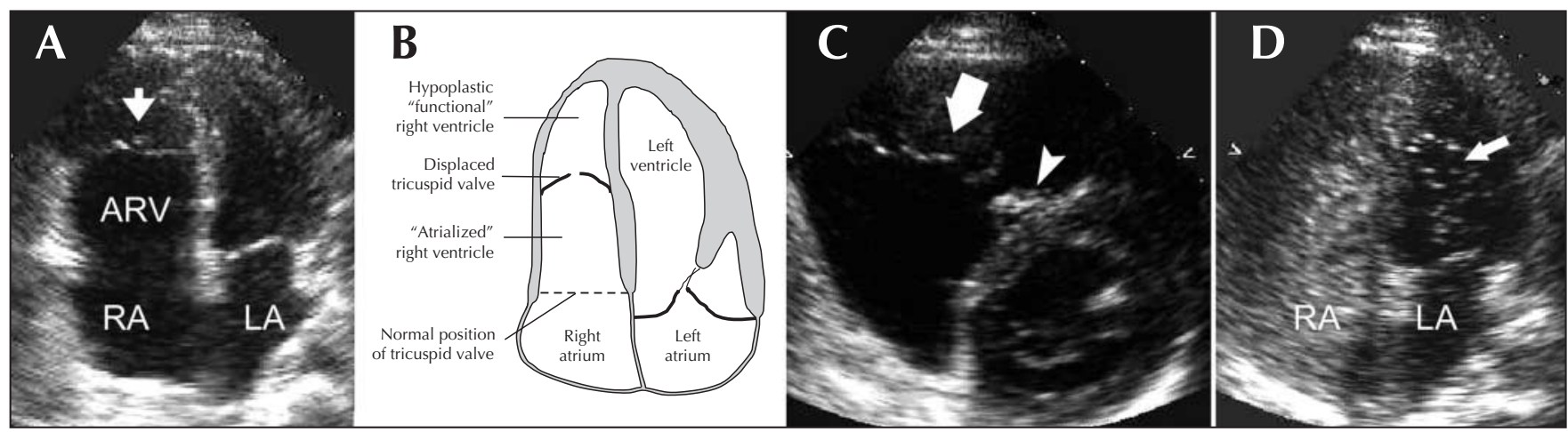

Fig. 2: A: Echocardiogram showing Ebstein's anomaly (apical displacement) of the tricuspid valve (arrow) and formation of an "atrialized" right ventricle (ARV). B: Anatomical sketch of echocardiogram in A. C: Echocardiogram showing elongated anterior tricuspid valve leaflet (arrow) and rudimentary septal leaflet (arrowhead). D: Contrast echocardiogram using saline, showing patent foramen ovale with right-to-left shunting and bubbles in the left ventricle (arrow). $R A=$ right atrium, $L A=l e f t$ atrium. 
7 he tricuspid valve anomaly described by Ebstein in 1864 consists of apical displacement of the septal and posterior tricuspid leaflets, which results

Box 1: Anatomical features and associated cardiac defects of Ebstein's anomaly ${ }^{1-3}$

Anatomical features

- Apical displacement of septal and posterior tricuspid valve leaflets

- Large anterior leaflet

- Rudimentary septal leaflet

- "Atrialized" right ventricular inlet (inflow region) with small outlet right ventricular region ("functional" ventricle)

- Right atrial enlargement due to tricuspid regurgitation

Associated congenital cardiac defects

- Pulmonary stenosis or atresia

- Ventricular septal defect

- Patent foramen ovale or atrial septal defect (in up to $50 \%$ of cases)

- Tetralogy of Fallot

- Patent ductus arteriosus

- Congenitally corrected transposition of the great arteries

Box 2: Clinical signs and manifestations of Ebstein's anomaly

- Fetal hydrops and intrauterine death

- Cyanosis

- due to right-to-left shunting at the atrial level

- often transitory in neonates

- may be accompanied by clubbing in adults

- Tricuspid regurgitation

- holosystolic murmur, best heard at the lower left sternal border with inspiration

- may occur without expected jugular venous distension owing to large and compliant right atrium

- Arrhythmias

- Wolff-Parkinson-White syndrome (in 25\% of cases)

- atrial flutter or fibrillation (in $25 \%-30 \%$ of cases)

- Heart failure

- due to severe tricuspid regurgitation, sustained arrhythmias or left ventricular fibrosis

- Paradoxical embolus

- from passage of thrombi formed in the venous circulation into the arterial circulation through an atrial septal defect

- Endocarditis in an enlarged right atrium functionally integrated with the inlet region of the right ventricle ("atrialized" right ventricle). The outlet and trabecular portions of the right ventricle constitute an often hypoplastic, "functional" ventricle (Box 1). Ebstein anomaly occurs in 5 per 100000 live births, accounting for $0.5 \%$ of all cases of congenital heart disease. ${ }^{1}$ Risk factors believed to be associated with the condition are a family history of Ebstein's anomaly or other congenital heart disease, northern European ancestry and maternal exposure to benzodiazepines or lithium. ${ }^{1-3}$ More than $30 \%$ of patients with Ebstein's anomaly have associated cardiac defects $^{1}$ (Box 1).

The clinical manifestations of Ebstein's anomaly (Box 2) depend on the degree of tricuspid valve malformation and consequent regurgitation, and any associated cardiac defects. ${ }^{2,3}$ Many patients first experience symptoms as adults, but the onset can occur after birth or in infancy or childhood. In newborns, the anomaly often presents as cyanosis and, in the absence of surgical repair, is associated with a $20 \%$ mortality in the first year of life. In infants, it may present as congestive heart failure and in children as an incidental murmur. In adults, the anomaly commonly presents with arrhythmias. Factors associated with a worse outcome are young age at diagnosis, male sex, cardiothoracic ratio of more than 0.65 and the presence of cyanosis. $^{2}$

The treatment of Ebstein's anomaly has to be tailored to the individual patient. Patients with heart failure and little impairment in functional capacity can be managed medically. Atrial arrhythmias without evidence of pre-excitation can be treated pharmacologically, whereas percutaneous radiofrequency ablation is indicated in the presence of an accessory pathway. In general, surgical intervention with tricuspid valve repair or replace- ment is restricted to patients with severe heart failure, cyanosis, intractable arrhythmias or paradoxical embolization (passage of thrombi from the venous circulation into the arterial circulation through a right-to-left shunt at the atrial level). Patients with Ebstein's anomaly should be assessed regularly for signs of deterioration in functional capacity, increasing cyanosis or presence of arrhythmia. Prophylaxis against infective endocarditis is warranted in all cases.

Electrocardiographic evidence of pre-excitation (delta wave on upstroke of QRS complex) is found in up to $0.25 \%$ of the general population. The incidental finding of pre-excitation in an otherwise asymptomatic patient with normal cardiac findings on physical examination does not warrant further investigation. The patient should be advised to report any symptoms suggestive of tachyarrhythmia. Patients with Wolff-ParkinsonWhite syndrome (pre-excitation and symptomatic tachyarrhythmia) should be referred to a specialist for electrophysiologic evaluation. The presence of pre-excitation and a tricuspid regurgitation murmur, as in the case we have described, should raise the suspicion of Ebstein's anomaly.

Constantin B. Marcu

Thomas J. Donohue

Hospital of Saint Raphael

Yale University

New Haven, Conn.

\section{References}

1. Correa-Villasenor A, Ferencz C, Neill CA, Wilson PD, Boughman JA. Ebstein's malformation of the tricuspid valve: genetic and environmental factors. The Baltimore-Washington Infant Study Group. Teratology 1994; 50:137-47.

2. Sondergaard L, Cullen S. Ebstein anomaly. In: Gatzoulis MA, Webb GD, Daubeney PEF, editors. Diagnosis and management of adult congenital heart disease. Edinburgh: Churchill Livingstone; 2003. p. 283-7.

3. Friedman WF, Silverman N. Congenital heart disease in infancy and childhood. In: Braunwald E, Zipes DP, Libby P, editors. Heart disease. 6th ed. Philadelphia: W.B. Saunders; 2001. p. 1564-6. 